\title{
Genetic adaptation of bacteria to chlorinated aromatic compounds
}

\author{
Jan Roelof van der Meer * \\ EAWAG, Ueberlandstr. 133, CH-8600 Dübendorf, Switzerland
}

\begin{abstract}
Genetic mechanisms in bacteria provide a continuous source of alterations in DNA sequences that may lead to favourable adaptations. Bacteria that use chlorinated aromatics as sole carbon and energy sources show evidence of these different genetic alterations. The distinct effects of single base-pair mutations on adaptation of bacterial strains (e.g. by changing the substrate specificity of a key metabolic enzyme or regulator protein) have been demonstrated in various studies. In addition to these small sequence modifications, intermolecular or intercellular gene exchange mechanisms can result in new strains with altered metabolic capabilities. The details of these evolutionary processes with respect to the metabolism of chlorobenzenes and chlorocatechols are reviewed in this manuscript.
\end{abstract}

Key words: Adaptation; Pseudomonads; Chlorinated aromatic compounds; Evolution

\section{Introduction}

Over the past few decades, the large scale industrial production and extensive use of synthetic chemicals in all levels of society have led to a wide distribution of harmful compounds in the environment. In almost any compartment of our environment (e.g. soil, air, water, and biota), traces of synthetic organic compounds can be detected. At many waste disposal sites or other point sources of contamination, concentrations of these chemicals may be so great that direct toxicological risks are encountered.

Microorganisms play a central role in the degradation of organic compounds and therefore are very important for the mineralization or

\footnotetext{
* Corresponding author. Tel.: $(+41-1) 823$ 5438; Fax: $(+41-1)$ 8235547
}

detoxification of toxic organic chemicals. Unfortunately, not all organic compounds are equally well biodegradable, and, in some cases, environmental conditions may be unfavourable for microbial activity. If the molecular structure of a compound is not commonly encountered in nature, microorganisms may not have the necessary degradative enzyme systems. The presence of substituents, such as halogen atoms, nitro- or sulfite groups, on otherwise easily degradable compounds may make the compound less accessible for biodegradation and thus more persistent in the environment $[1,2]$.

It has been shown that microbial populations may adapt to use previously persistent compounds as novel carbon and energy sources [3-5]. Such an adaptation may be caused by the selection of mutant strains which have acquired novel metabolic activities or altered enzymatic specificities. Here I discuss some of the genetic mecha- 
nisms which may have resulted in the formation of the metabolic pathway of chlorinated benzene degradation in pseudomonads.

\section{Genetic mechanisms for adaptation}

A wide variety of processes exist that cause changes in existing genetic material and result in altered metabolic functions. The details of the different genetic mechanisms in adaptation to xenobiotic compounds have recently been reviewed elsewhere [6,7]. When considering the different genetic mechanisms involved in evolution and alterations of DNA sequences, a distinction should be made between vertical and horizontal evolutionary processes [8]. Vertical processes are those which lead to a divergence in DNA sequence in daughter cells, due to the accumulation of mutations. These mutations can be single base-pair changes or those leading to larger sequence changes, e.g. deletions and duplications. The effects of point mutations on enzyme specificity or on effector recognition by regulator proteins have been well established [9-12], and it has become clear that these processes can have direct consequences for the adaptation of strains to xenobiotic compounds. Other possible processes of sequence divergence, e.g. slipped strand mispairing, can lead to more extensive sequence changes and may be a general driving force for the divergence of gene sequences $[13-15]$. The effect of such a process in microorganisms, however, has not yet been well investigated.

Horizontal processes are those which cause an exchange of DNA sequences between the genome of two different organisms (intercellular movement), or between different DNA molecules, e.g. within the chromosome and extrachromosomal elements inside one organism (intermolecular movement) [8]. Horizontal movement of genetic information may be caused by recombination or other mechanisms of gene exchange, e.g. conjugation, transduction, or transformation. It has become very clear that horizontal gene exchange plays an important role in the adaptation of microorganisms to xenobiotic compounds [6]. The list of bacteria with self-transmissable plasmids encoding the degradation of aromatic or toxic organic compounds is extensive [16]. Although many of these plasmids have a similar backbone structure encoding probably replication and transfer functions, they carry different catabolic genes [17]. This strongly suggests the existence of processes by which plasmids can acquire genes or gene clusters and subsequently disseminate them in a microbial population $[18,19]$. Such a recent example of horizontal gene exchange has been the discovery of transposable elements of different families containing catabolic genes. The $x y l$ and nah genes are located on Tn3-type transposons, $\operatorname{Tn} 4561(56 \mathrm{~kb})[20]$ and $\operatorname{Tn} 4655(55 \mathrm{~kb})$ [21], respectively. Other elements which have been described include Tn 5271, encoding 4-chlorobenzoate metabolism [22], Tn4371, for 4-chlorobiphenyl metabolism [23], IS931, associated with the 2,4,5-trichlorophenoxyacetic acid genes [24], the $D E H$ element, which carries the dehalogenase genes of Pseudomonas putida PP3 [25], and Tn 5280 of the chlorobenzene plasmid pP51 [26] (see below). Some of these elements reside on the chromosome (such as IS931, Tn 437I, and DEH), whereas the others were originally isolated from plasmids.

\section{Evolution of the metabolic pathway for chloro- benzene degradation}

Since very few bacteria had been described which were able to degrade chlorobenzenes completely, we considered these compounds suitable substrates for evolutionary studies of bacterial adaptation. Characterization of Pseudomonas sp. strain P51, capable of degrading 1,2,4-trichlorobenzene, 1,2-dichloro- and 1,4-dichlorobenzene, along with strains isolated by others [5,27-29], led to a reasonably good picture of the metabolic pathway for chlorobenzene degradation and of the different genes which are involved in this pathway [26,29-31]. The first enzymes of the pathway, a three-component aromatic ring dioxygenase and a benzene glycol dehydrogenase, catalyze the incorporation of a dioxygen molecule into the aromatic ring and the subsequent dehydrogenation which gives rise to a chlorinated 
catechol. The chlorinated catechol is then cleaved in a second dioxygenation reaction, catalyzed by chlorocatechol 1,2-dioxygenase, and further degraded, via a number of different chlorinated intermediates, probably to (chloro-)3-oxoadipate. In strain P51 the different genes encoding these metabolic steps were found on a $110-\mathrm{kb}$ plasmid [29]. Three different transcriptional units were found: (i) the 'upper pathway' cluster, containing the genes encoding the chlorobenzene dioxygenase and the chlorobenzene glycol dehydrogenase; (ii) the 'chlorocatechol oxidative' cluster, encoding the genes for the conversion of chlorocatechols (see below); and (iii) the regulatory gene $t c b R$, which encodes a transcriptional activator for the chlorocatechol oxidative operon

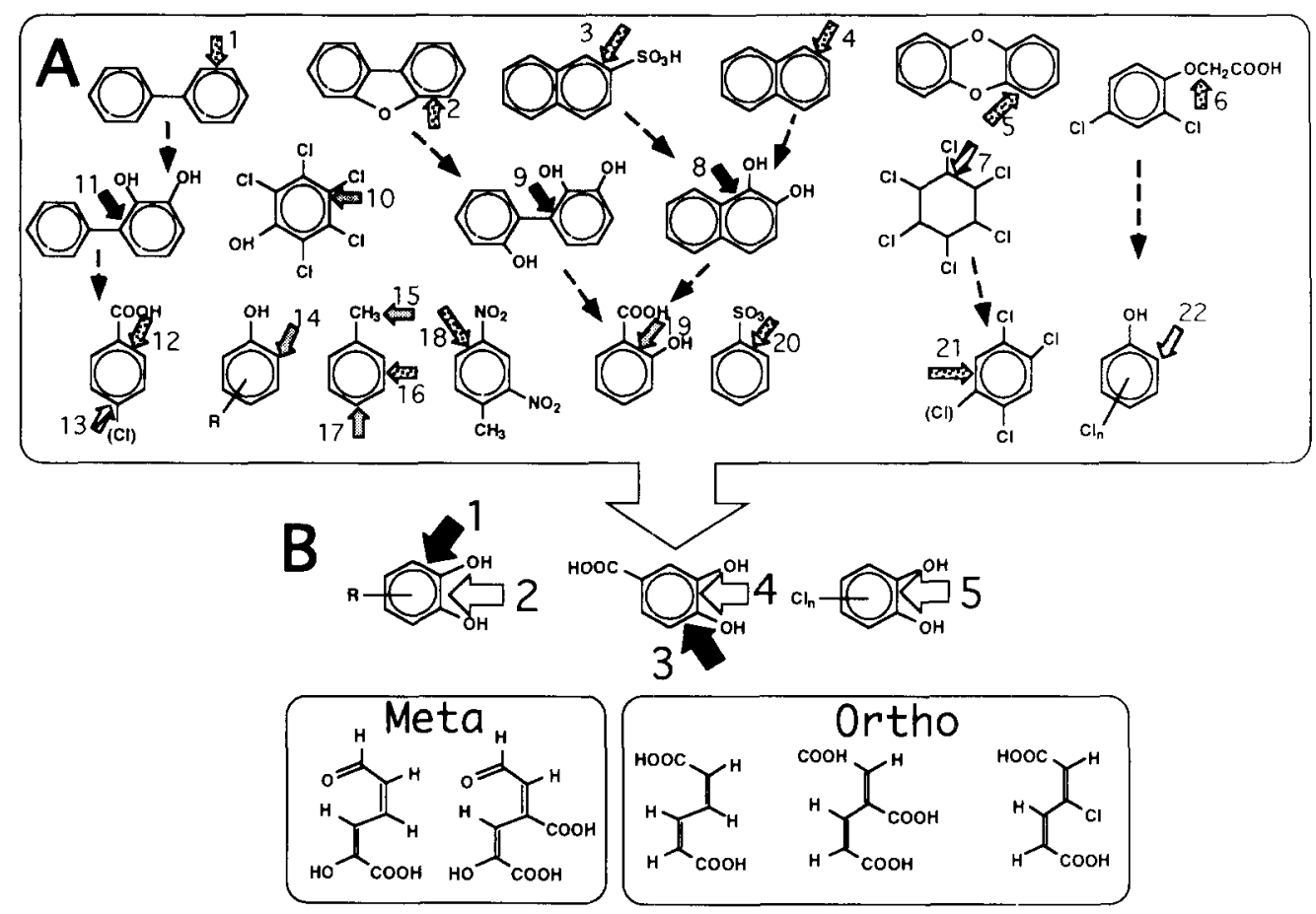

Fig. 1. Schematic representation of metabolic channeling in the aerobic degradation of aromatic compounds by bacteria. (A) A number of different aromatic compounds and the positions at which initial enzymatic attack can take place (indicated by numbered arrows). Dotted arrows between different structures indicate that this particular compound can occur as intermediate in the degradation of the previous one. Numbers: 1, biphenyl dioxygenase [82]; 2, dibenzofuran dioxygenase [83]; 3, naphthalenesulfonic acid dioxygenase [84]; 4, naphthalene dioxygenase [85,86]; 5, dibenzo-p-dioxin dioxygenase [83]; 6, '2,4-dichlorophenoxyacetate monooxygenase' [69], 2,4-D/ $\alpha$-ketoglutarate dioxygenase [49]; 7, $\gamma$-HCH dehydrochlorinase [87]; 8, 1,2-dihydroxynaphthalene dioxygenase [33,84]; 9, 2,2',3-trihydroxybiphenyl dioxygenase [56]; 10, pentachlorophenol 4-monooxygenase [88,89]; 11, 2.3-dihydroxybiphenyl dioxygenase [90]; 12, benzoate 1,2-dioxygenase [44]; 13, 4-chlorobenzoate dehalogenase [58]; 14, phenol hydroxylase [50]; 15, xylene monooxgenase [91]; 16, toluene dioxygenase [32]; 17, toluene 4-monooxygenase [51]; 18 , dinitrotoluene dioxygenase [92]; 19, salicylate hydroxylase [47]; 20, benzene sulfonate dioxygenase [93]; 21, chlorobenzene dioxygenase [29]; 22, 2,4-dichlorophenol hydroxylase [38]. Different shadings indicate enzyme families with sequence homologies or with comparable activities: (black). extradiol dioxygenases; (stippled), aromatic ring dioxygenase; (grey dotted), monooxygenases and hydroxylases; (striped), dehalogenase activities. (B) The different ortho dihydroxylated central intermediates. Ring cleavage of these intermediates takes place as indicated by the arrows. Open arrows represent intradiol dioxygenases, filled arrows the extradiol dioxygenases. Numbers: 1, catechol 2,3-dioxygenase; 2, catechol 1,2-dioxygenase; 3, protocatechuate 4,5-dioxygenase; 4, protocatechuate 3,4-dioxygenase; 5, chlorocatechol 1,2-dioxygenase. Below this are shown the ring cleavage products of the intradiol- (ortho-) and extradiol- (meta) cleavage reactions. No complete overview of all possible reactions is intended. 
[26,29-31]. The upper pathway gene cluster in strain P51 is flanked by two iso-insertion elements, IS 1066 and IS 1067. This complete element, Tn5280, was shown to be a functional transposon, able to insert in single copy and at random into the genome [26].

As a result of these analyses, it appears that the metabolic pathway for chlorobenzene degradation in strain P51 developed from two different genetic elements. The transposable element containing the genes for the aromatic ring dioxygenase and the benzene glycol dehydrogenase, i.e. Tn 5280, may have originated in bacteria degrading toluene by direct dioxygenation, such as $P$. putida F1 [32]. The dioxygenase in this strain was shown to have a broad substrate range, and could oxidize chlorinated benzenes to the corresponding dihydrodiols [32]. If such a dioxygenase gene cluster became captured by two copies of an insertion element, i.e. IS 1066 and IS1067, successful transfer of the dioxygenase transposon to a catabolic plasmid containing a chlorocatechol oxidative operon, could provide the resulting transconjugant strain with the necessary genetic information to carry out complete chlorobenzene degradation. Strain P51, then, provides a nice example of different evolutionary mechanisms which may be required for the generation of a new catabolic pathway, i.e. (i) recombination events involving horizontal gene transfer, and (ii) vertical evolution of specialized enzyme systems for new (chlorinated) substrates (see below).

\section{Convergence and variations in metabolic path- ways for (chloro-) aromatic compounds}

It has been established that metabolic pathways of aromatic compounds in bacteria generally follow similar strategies and involve a limited number of central steps. Pathways for aerobic degradation of aromatics apparently converge to form a relatively small number of intermediates (Fig. 1). These intermediates carry at least two hydroxyl groups (in ortho or para positions) and can contain other substituent groups. They are then cleaved either by intradiol dioxygenase enzymes (ortho cleavage) or by extradiol dioxyge- nases (meta cleavage). The intradiol and extradiol dioxygenases appear to have no significant similarities on the amino acid level, and therefore are not evolutionary closely related [33]. Within the extradiol dioxygenases and intradiol dioxygenases. different enzyme groups also exist with relatively little sequence similarity. The archetype extradiol dioxygenase, catechol 2,3-dioxygenase (encoded by the $x y l E$, nahH or $d m p B$ genes) (Fig. 1B), does not show significant sequence similarity with the extradiol enzyme protocatechuate 4,5-dioxygenase [34]. Of the intradiol dioxygenases, three subgroups have been described: catechol 1,2-dioxygenase (encoded by (atA of Acinetobacter calcoaceticus or P. putida) [14], protocatechuate 3,4-dioxygenase (encoded by the pcaHG genes of e.g. P. putida, P. cepacia, $A$. calcoaceticus) [35-37], and chlorocatechol 1,2-dioxygenase (encoded by $t c b C$ of Pseudomonas sp. strain P51 [30], tfdC of Alcaligenes eutrophus [38,39], or clcA of $P$. putida pAC27 [40], and described for Pseudomonas sp. B13 [41]).

Among the enzymes which catalyze the initial steps in aromatic degradation pathways, different classes are found with extensive homology to each other and to other enzymes of the central pathways (Fig. 1), suggesting similar evolutionary strategies. The most important class of these enzymes is probably that of the aromatic ring dioxygenases, which catalyze insertion into the aromatic ring of two hydroxyl groups derived from molecular oxygen and cofactors such as NADH (recently reviewed in references $[42,43]$ ). It currently appears that all of these dioxygenases are multi-component enzymes with three or four different protein subunits. These proteins comprise a short electron transfer chain, by which electrons are transferred from NADH, via a reductase and a ferredoxin, to the terminal oxidase. The reductase and the ferredoxin may be combined as two domains of one protein molecule, as is the case for the toluate and benzoate dioxygenases $[13,44]$. In some cases, the different protein subunits of the aromatic ring dioxygenases share significant amino acid sequence homology, e.g. the two subunits which make up the terminal oxidase of the toluate dioxygenase and those of the naphthalene, toluene or biphenyl dioxygenase $[44,45]$. 
Many other aromatic ring dioxygenases have not yet been characterized on the DNA sequence level, and comparison can only be made on the basis of biochemical information [43].

Another class of enzyme activities catalyzing initial steps in aromatic metabolism are the monooxygenases or hydroxylases. These catalyze the incorporation of a single hydroxyl group on the aromatic ring or oxidize alkyl side chains. Several different enzyme groups are found which are not significantly related on amino acid sequence level. Single component aromatic ring flavoprotein hydroxylases are exemplified by $p$ hydroxybenzoate hydroxylase, with a monomer size of $45 \mathrm{kDa}$ [46]. An overall amino acid sequence identity of $25 \%$ was found between $p$-hydroxybenzoate hydroxylase and salicylate hydroxylase (encoded by the NAH plasmid gene $n a h G$ ) [47], whereas 2,4-dichlorophenol hydroxylase (encoded by the gene $t f d B$ of plasmid pJP4) [38] and phenol hydroxylase (encoded by pheA) [48] are substantially larger, and only share significant sequence similarity in two regions, one of which may be involved in FAD binding. The 2,4-dichlorophenoxyacetic acid monooxygenase (encoded by tfdA on plasmid pJP4) is not related to these single component monooxygenases [43]. Recently it was reported, however, that the enzyme is a ferrous-ion- and $\alpha$-ketoglutarate-dependent dioxygenase, rather than a monooxygenase [49]. Multicomponent aromatic ring monooxygenases are also found, e.g. phenol hyxdroxylase from Pseudomonas CF600 (encoded by the dmpKLMNOP genes) [50], and toluene 4-monooxygenase from $P$. mendocina KR1 (encoded by the tmoABCDE genes) [51]. These two enzyme complexes have three protein subunits in common [51]. Furthermore, the TmoC ferredoxin and TodB ferredoxin of the aromatic ring dioxygenases share $32 \%$ amino acid sequence identity and therefore may be of similar evolutionary origin [51]. Another class of monooxygenase activities is found in enzymes which oxidize alkyl side groups on aromatic rings, such as xylene monooxygenase [52] and toluene sulfonate methyl monooxygenase [53]. These two enzymes have biochemically distinct properties, however, and do not appear strongly related [53].
Several other enzymatic steps are required to convert aromatic substrates to the hydroxylated intermediates. Very interesting from an evolutionary point of view are the extradiol cleavage enzymes, 2,3-dihydroxybiphenyl 1,2-dioxygenase (BphC) [54] and 1,2-dihydroxynaphthalene dioxygenase (NahC) [33], which share significant overall amino acid sequence similarity with the catechol 2,3-dioxygenases XylE, NahH [33] and DmpB [55]. Other extradiol cleavage enzymes such as 2,2',3-trihydroxybiphenyl dioxygenase [56] may also belong to this large protein family. Dehydrogenases catalyze the reduction of the dihydrodiol compounds formed by the activity of the aromatic ring dioxygenases to form catechols. These dehydrogenases were shown to be related to one another and to belong to the family of short-chain alcohol dehydrogenases [57]. Unique enzyme activities found in the first steps of aromatic metabolism may have been recruited into these pathways from yet unknown evolutionary origin, e.g. dehalogenating enzymes (4-chlorobenzoate dehalogenase of Pseudomonas sp. CBS3 [58] or dehydrochlorinase of $P$. paucimobilis UT6 [59].

In conclusion, several classes of enzymes catalyzing the early stages of transformation of aromatic compounds are found (Fig. 1). Enzymes within these classes, such as the multi-component dioxygenases, share significant sequence similarities with one another. Some of them, e.g. the extradiol dioxygenases appear to form evolutionary related protein families with enzymes from 'deeper' metabolic branches, such as catechol 2,3-dioxygenase. This evolutionary relatedness and the genetic organization of catabolic gene clusters [6] suggest genetic processes by which DNA fragments containing several genes (sometimes referred to as 'gene modules' or 'gene cassettes') or gene fragments are combined to form new metabolic pathways or protein activities. An example of the existence of such gene modules may be a DNA fragment containing the genes for the aromatic ring dioxygenase and the benzene glycol dehydrogenase (Fig. 2). These genes can be found at totally different positions in the genomes of different bacteria [6]. Other examples of some putative gene modules within aromatic degradation pathways, are the meta 
cleavage pathway genes (in stricter sense) and the genes for a modified ortho cleavage pathway. The meta cleavage pathway genes have been found in almost identical genetic organization as part of the operons for salicylate degradation (nah genes), toluate and metatoluate degradation ( $x y l$ genes), phenol degradation ( $d m p$ genes), and toluene degradation (tod genes) [6]. The reactions catalyzed by these gene modules are shown in Fig. 2.

\section{Evolution of the chlorocatechol oxidative pathway}

An important central pathway for the aromatic degradation of chlorinated compounds in bacteria is the chlorocatechol oxidative pathway or modified ortho cleavage pathway $[2,41,60]$. Chlorinated catechols are converted by a specific set of enzymes to finally 3-oxoadipate [61,62], which may carry one chlorine atom, depending on the amount of chlorine substituents on the catechol. Chlorocatechol 1,2-dioxygenase, the first enzyme of the pathway, is an enzyme that is approximately $40 \%$ identical to the normal catechol 1,2 -

\section{Aromatic ring dioxygenase/dehydrogenase}

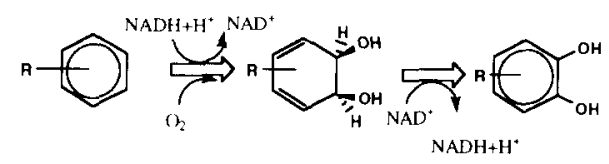

\section{Modified ortho cleavage pathway}

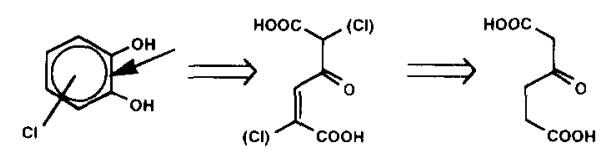

\section{Meta cleavage pathway}

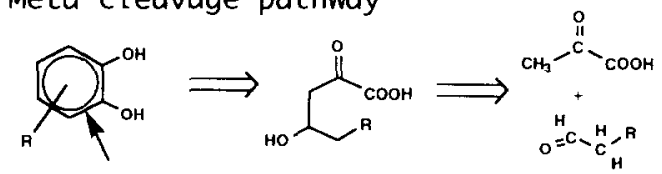

Fig. 2. Metabolic reactions catalyzed by enzymes encoded on three putative gene modules. Open arrows between different intermediates indicate that more than one enzymatic step is required, closed arrows depict single enzymatic steps. Black arrows indicate the cleavage site for the catechol dioxygenase. dioxygenase, but that has a much wider substrate range with respect to conversion of chlorocatechols $[30,63]$. Chloromuconate cycloisomerase, the next enzyme in the pathway, can have very different substrate specificities depending on the strain from which it was isolated [64]. Chloromuconate cycloisomerases have a high sequence similarity to the muconate cycloisomerase (approximately $40 \%$ overall amino acid sequence identity) [30]. Some chloromuconate cycloisomerases are thought to have an active dechlorination mechanism, as opposed to the spontaneous dechlorination in the conversion of 3-chloromuconate by muconate cycloisomerase. The chlorodienelactones which are formed by the activity of chloromuconate cycloisomerase are then further transformed by dienelactone hydrolase and by maleylacetate reductase.The latter enzyme may also have a dechlorinating activity [62].

The genetic organization of the chlorocatechol oxidative pathway differs substantially from both that of the normal ortho cleavage pathway, such as that characterized from Acinetobacter calcoaceticus, and that of the protocatechuate pathway $[14,35,36,44]$. In the normal ortho cleavage pathway, cat $A$ encoding catechol 1,2-dioxygenase, is separated from the other genes of the pathway (Fig. 3A). The only genes in the protocatechuate pathway with significant similarity to those of the modified ortho pathway genes, are the pcaHG genes encoding the protocatechuate 3,4-dioxygenase (Fig. 3B). However, these show even less conservation in their localization within the pathway gene clusters (Fig. 3B). In the chlorocatechol oxidative pathway, the gene encoding the chlorocatechol 1,2-dioxygenase is directly coupled to the chloromuconate cycloisomerase gene [30]. Interestingly, only these two genes are common to the ortho and modified ortho pathways. After the stage of the cycloisomerase, the pathways diverge. In the operons for the chlorocatechol oxidative pathway, we find evidence for DNA rearrangements after the chloromuconate cycloisomerase gene [30]. Two of the three different characterized operons have an extra DNA fragment between the genes encoding chloromuconate cycloisomerase and dienelactone hydrolase, whereas the other has only remnants of this 
DNA fragment. It could be that the first part of the operon, i.e. the chlorocatechol 1,2-dioxygenase and chloromuconate cycloisomerase genes, became fused with a different set of genes from another origin, since the latter genes have no apparent sequence homology with genes from the normal ortho cleavage pathway.

A special case is required for the different regulatory genes which are involved in the regulation of the (chloro)catechol oxidative pathways. Regulatory genes for the ortho cleavage pathways include catM ( $A$. calcoaceticus) [65], catR ( $P$. putida) [66,67], tcbR (Pseudomonas sp. strain P51) [31], clcR ( $P$. putida pAC27) [68], and tfdS ( $A l$ caligenes eutrophus JMP134) [69,70]. All encode proteins which belong to the group of LysR transcriptional activators and are located at a similar position with respect to the rest of the pathway genes which they regulate (Fig. 3), suggesting that they form an ancient type of regulation. Although CatR and ClcR respond to the inducer muconate, it is not known to what extent the various regulators differ in their inducer specificity or in recognition of DNA-binding sites at the operator. It will be interesting to further analyze changes that may have occurred in the different modified ortho cleavage pathways before they obtained their final form and to determine the possible 'original' substrates for this pathway in bacteria.

\section{Concluding remarks}

Comparative studies in bacteria have revealed evidence of evolutionary processes that created or modified different metabolic pathways, e.g.

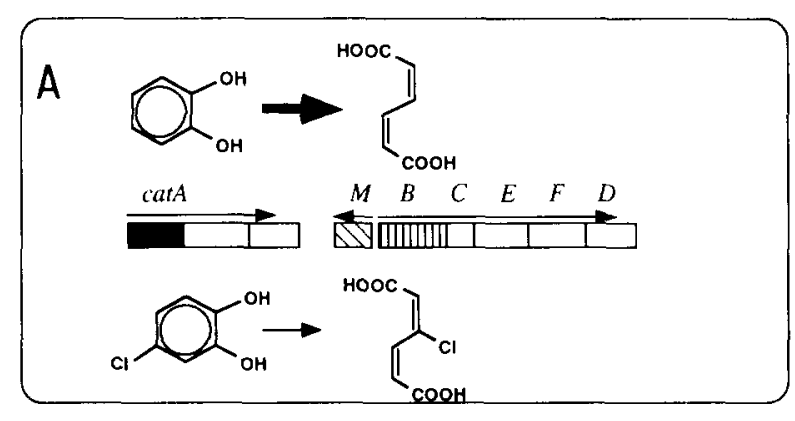

B

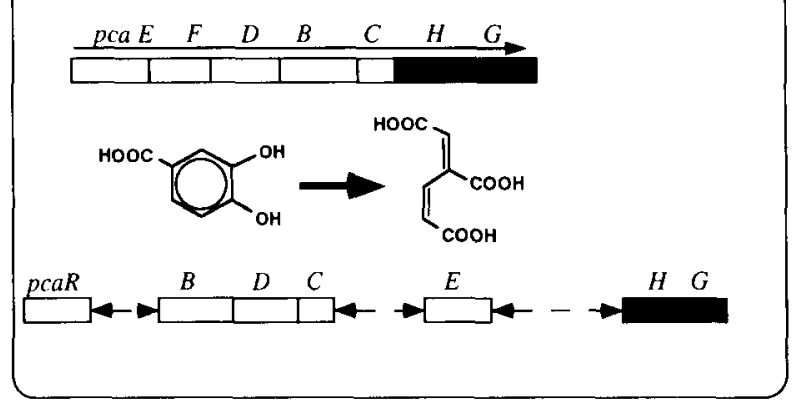

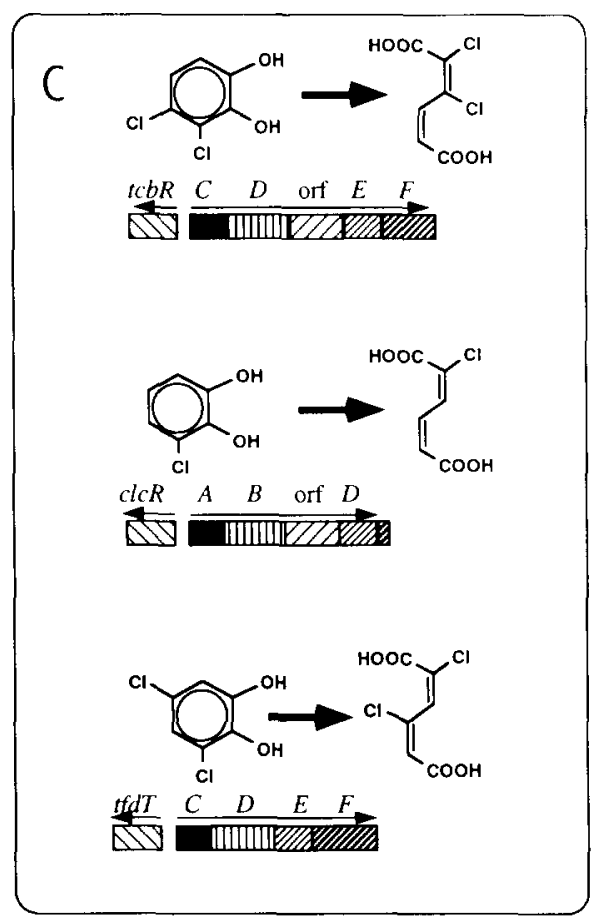

Fig. 3. Comparison of the genetic organization of the different ortho cleavage pathways and reactions catalyzed by the intradiol dioxygenases. (A) Normal ortho cleavage pathway encoded by the catA, cat $M$, and catBCEFD genes of $A$. calcoaceticus [14,15,65]. (B) Protocatechuate pathway genes of $A$. calcoaceticus and of $P$. putida (below) $[35,36,94]$. (C) Modified ortho cleavage pathways encoded by the $t c b C D E F$ operon of Pseudomonas sp. strain P51 [29-31], clcABD of P. putida (pAC27) [40,68], and tfdCDEF of $A$. eutrophus JMP134 $[38,39]$. The genes encoding the intradiol cleavage enzymes are shown in black; the reactions these enzymes catalyze are depicted inside the panels. A small arrow indicates a side reaction with less efficiency. Arrows directly above the gene clusters indicate the direction of transcription. Similar shadings in the genes represent significant sequence similarities between the 
those for degradation of xenobiotic compounds. It has become clear that some specialized functions, e.g. enzymes for conversion of chlorinated aromatics, probably evolved prior to the introduction of xenobiotics into the environment. On the other hand, new evolutionary events such as horizontal gene transfer processes or point-mutations are still taking place and can have an important impact on the adaptibility of strains. The question of whether the occurrence of large quantities of synthetic, toxic compounds has led to a rapid evolution of new bacterial genotypes, however, is still open. Several studies have recently indicated that mutations would be possible in bacteria which are 'environmentally induced' [71-76], although the issue is subject to debate [77,78]. It will be very interesting to find more evidence of regulatory circuits in bacteria that, sensing changing environments [79] or the presence of toxic compounds [80,81], switch on mechanisms leading to favorable genetic alterations.

\section{Acknowledgement}

I would like to thank Flynn Picardal for critical review of the manuscript.

\section{References}

1 Reineke, W. and Knackmuss, H.-J. (1988) Microbial degradation of haloaromatics. Annu. Rev. Microbiol. 42. 263-287.

2 Reineke, W. (1984) Microbial degradation of halogenated aromatic compounds. In: Microbial Degradation of Organic Compounds (Gibson, D.T., Ed.), pp. 319-360. Marcel Dekker, New York, NY.

3 Aelion. C.M., Swindoll, C.M. and Pfaender, F.K. (1987) Adaptation to and biodegradation of xenobiotic compounds by microbial communities from a pristine aquifer. Appl. Environ. Microbiol. 53, 2212-2217.

4 Barkay, T. and Pritchard, H. (1988) Adaptation of aquatic microbial communities to pollutant stress. Microbiol. Sci. $5,165-169$.

5 Spain, J.C. and van Veld, P.A. (1983) Adaptation of natural microbial communities to degradation of xenobiotic compounds: effects of concentration, exposure, time, inoculum, and chemical structure. Appl. Environ. Microbiol. $45,428-435$.
6 Van der Meer, J.R., de Vos, W.M., Harayama, S. and Zehnder, A.J.B. (1992) Molecular mechanisms of genetic adaptation to xenobiotic compounds. Microbiol. Rev. 56. $677-694$

7 Harayama. S. and Timmis. K.N. (1992) Aerobic biodegradation of aromatic hydrocarbons by bacteria. In: Degradation of Environmental Pollutants by Microorganisms and Their Metalloenzymes (Sigel, H. and Sigel, A., Eds.), pp. 99-157. Marcel Dekker, New York. NY.

8 Amabile-Cuevas, C.F. and Chicurel, M.E. (1992) Bacterial plasmids and gene flux. Cell 70, 189-199.

9 Abril, M.-A., Michan, C. Timmis, K.N. and Ramos, J.L. (1989) Regulator and enzyme specificites of the TOL plasmid-encoded upper pathway for degradation of aromatic hydrocarbons and expansion of the substrate range of the pathway. J. Bacteriol. 171, 6782-6790.

10 Ramos, J.L., Stolz, A., Reineke, W. and Timmis, K.N. (1986) Altered effector specificities in regulators of gene expression: TOL plasmid $x y l S$ mutants and their use to engineer expansion of the range of aromatics degraded by bacteria. Proc. Natl. Acad. Sci. USA 83, 8467-8471.

11 Clarke, P.H. (1984) The evolution of degradative pathways. In: Microbial Degradation of Organic Compounds (Gibson, D.T.. Eds.), pp. 11-27. Marcel Dekker. New York. NY.

12 Zhou. L.. Timmis, K.N. and Ramos, J.L. (1990) Mutations leading to constitutive expression from the TOL plasmid meta-cleavage pathway operon are located at the C-terminal end of the positive regulator protein XylS.J. Bacteriol. 172. 3707-3710.

13 Harayama, S.. Rekik, M., Bairoch. A.. Neidle. E.L. and Ornston, L.N. (1991) Potential DNA slippage structures acquired during evolutionary divergence of Acinetobacter calcoaceticus chromosomal ben $A B C$ and Psetudomonas putida TOL pWWO plasmid $x y l X Y Z$, genes encoding benzoate dioxygenases. J. Bacteriol. 173, 7540-7548.

14 Neidle, E.L., Hartnett, C.. Bonitz, S. and Ornston, L.N. (1988) DNA sequence of the Acinetobacter calcoaceticus catechol 1,2-dioxygenase 1 structural gene catA: evidence for evolutionary divergence of intradiol dioxygenases by acquisition of DNA sequence repetitions. J. Bacteriol. 170. 4874-4880

15 Ornston, L.N., Houghton, J., Neidle, E.L. and Gregg, L.A. (1990) Subtle selection and novel mutation during evolutionary divergence of the $\beta$-ketoadipate pathway. In: Pseudomonas: Biotransformations. Pathogenesis and Evolving Biotechnology (Silver, S., Chakrabarty, A.M., Iglewski, B. and Kaplan, S., Eds.), pp. 207-225. American Society for Microbiology, Washington, D.C.

16 Frantz, B. and Chakrabarty, A.M. (1986) Degradative plasmids in Pseudomonas. In: The Biology of Pseudomonas (Sokatch, J.R., Eds.), pp. 295-323. Academic Press, New York, NY.

17 Burlage, R.S., Bemis, L.A., Layton, A.C., Sayler, G.S. and Larimer, F. (1990) Comparative genetic organization of incompatibility group P degradative plasmids. J. Bacteriol. 172. $6818-6825$. 
18 Collis, C.M. and Hall, R.M. (1992) Gene cassettes from the insert region of integrons are excised as covalently closed circles. Mol. Microbiol. 6, 2875-2885.

19 Sykora. P. (1992) Macroevolution of plasmids - a model for plasmid speciation. J. Theor. Biol. 159, 53-65.

20 Tsuda, M. and Iino, T. (1987) Genetic analysis of a transposon carrying toluene degrading genes on a TOL plasmid pWW0. Mol. Gen. Genet. 210, 270-276.

21 Tsuda. M. and Iino, T. (1990) Naphthalene degrading genes on plasmid NAH7 are on a defective transposon. Mol. Gen. Genet. 223, 33-39.

22 Nakatsu, C., Ng, J., Singh, R., Straus, N. and Wyndham, C. (1991) Chlorobenzoate catabolic transposon $\operatorname{Tn} 5271$ is a composite class I element with flanking class II insertion sequences. Proc. Natl. Acad. Sci. USA 88, 8312-8316.

23 Springael, D., Kreps, S. and Mergeay, M. (1993) Identification of a catabolic transposon. Tn 4371 , carrying biphenyl and 4-chlorobiphenyl degradation genes in Alcaligenes eutrophus A5. J. Bacteriol. 175, 1674-1681.

24 Tomasek, P.H., Frantz, B., Sangodkar, U.M.X., Haugland, R.A. and Chakrabarty, A.M. (1989) Characterization and nucleotide sequence determination of a repeat element isolated from a 2,4,5-T degrading strain of Pseudomonas cepacia. Gene 76, 227-238.

25 Thomas, A.W., Slater, J.H. and Weightman, A.J. (1992) The dehalogenase genes dehl from Pseudomonas putida PP3 is carried on an unusual mobile genetic element designated DEH. J. Bacteriol. 174, 1932-1940.

26 Van der Meer, J.R., Zehnder, A.J.B. and de Vos, W.M. (1991) Identification of a novel composite transposable element, Tn5280, carrying chlorobenzene dioxygenase genes of Pseudomonas sp. strain P51. J. Bacteriol. 173, 7077-7083.

27 Sander, P., Wittich, R.-M., Fortnagel, P., Wilkes, H. and Francke, W. (1991) Degradation of 1,2,4-trichloro- and 1,2,4,5-tetrachlorobenzene by Pseudomonas strains. Appl. Environ. Microbiol. 57, 1430-1440.

28 Haigler, B.E., Nishino, S.F. and Spain, J.C. (1988) Degradation of 1,2-dichlorobenzene by a Pseudomonas sp. Appl. Environ. Microbiol. 54, 294-301.

29 Van der Meer, J.R., van Neerven, A.R.W., de Vries, E.J., de Vos, W.M. and Zehnder, A.J.B. (1991) Cloning and characterization of plasmid-encoded genes for the degradation of 1,2-dichloro-, 1,4-dichloro-, and 1,2,4-trichlorobenzene of Pseudomonas sp. strain P51. J. Bacteriol. 173, 6-15.

30 Van der Meer, J.R., Eggen, R.I.L., Zehnder, A.J.B. and de Vos, W.M. (1991) Sequence analysis of the Pseudomonas sp. strain P51 tcb gene cluster, which encodes metabolism of chlorinated catechols: evidence for specialization of catechol 1,2-dioxygenases for chlorinated substrates. J. Bacteriol. 173, 2425-2434.

31 Van der Meer, J.R., Frijters, A.C.J., Leveau, J.H.J., Eggen, R.I.L., Zehnder, A.J.B. and de Vos, W.M. (1991) Characterization of the Pseudomonas sp. strain P51 gene $t c b R$, a LysR-type transcriptional activator of the $t c b C D E F$ chlo- rocatechol oxidative operon, and analysis of the regulatory region. J. Bacteriol. 173, 3700-3708.

32 Gibson, D.T., Zylstra, G.J. and Chauhan, S. (1990) Biotransformations catalyzed by toluene dioxygenase from Pseudomonas putida Fl. In: Pseudomonas: Biotransformations, Pathogenesis and Evolving Biotechnology (Silver, S., Chakrabarty, A.M., Iglewski, B. and Kaplan, S., Eds.), pp. 121-133. American Society for Microbiology, Washington, D.C.

33 Harayama, S. and Rekik, M. (1989) Bacterial aromatic ring-cleavage enzymes are classified into two different gene families. J. Biol. Chem. 264, 15328-15333.

34 Noda, Y., Nishikawa, S., Shiozuka, K.-I., Kadokura, H., Nakajima, H., Yoda, K., Katayama, Y., Morohoshi, N., Haraguchi, T. and Yamasaki. M. (1990) Molecular cloning of the protocatechuate 4,5-dioxygenase genes of Pseudomonas paucimobilis. J. Bacteriol. 172. 2704-2709.

35 Hughes, E.J., Shapiro, M.K.. Houghton, J.E. and Ornston, L.N. (1988) Cloning and expression of pca genes from Pseudomonas putida in Escherichia coli. J. Gen. Microbiol. 134, 2877-2887.

36 Hartnett, C., Neidle, E.L., Ngai, K.-L. and Ornston, L.N. (1990) DNA sequences of genes encoding Acinetobacter calcoaceticus protocatechuate 3,4-dioxygenase: evidence indicating shuffling of genes and of DNA sequences within genes during their evolutionary divergence. J. Bacteriol. $172,956-966$.

37 Zylstra, G.J., Olsen, R.H. and Ballou, D.P. (1989) Genetic organization and sequence of the Pseudomonas cepacia genes for the alpha and beta subunits of protocatechuate 3,4-dioxygenase. J. Bacteriol. 171, 5915-5921.

38 Perkins, E.J., Gordon, M.P., Caceres, O. and Lurquin, P.F. (1990) Organization and sequence analysis of the 2,4-dichlorophenol hydroxylase and dichlorocatechol oxidative operons of plasmid pJP4. J. Bacteriol. 172, 23512359.

39 Don, R.H., Weightman, A.J., Knackmuss, H.-J. and Timmis, K.N. (1985) Transposon mutagenesis and cloning analysis of the pathways for degradation of 2,4-dichlorophenoxyacetic acid and 3-chlorobenzoate in Alcaligenes eutrophus JMP134(pJP4). J. Bacteriol. 161, 85-90.

40 Frantz, B. and Chakrabarty, A.M. (1987) Organization and nucleotide sequence determination of a gene cluster involved in 3-chlorocatechol degradation. Proc. Natl. Acad. Sci. USA 84, 4460-4464.

41 Schmidt, E., Remberg, G. and Knackmuss, H.-J. (1980) Chemical structure and biodegradability of halogenated aromatic compounds. Halogenated muconic acids as intermediates. Biochem. J. 192, 331-337.

42 Mason, J.R. and Cammack, R. (1992) The electron-transport proteins of hydroxylating bacterial dioxygenases. Annu. Rev. Microbiol. 46, 277-305.

43 Harayama, S., Kok, M. and Neidle, E.L. (1992) Functional and evolutionary relationships among diverse oxygenases. Annu. Rev. Microbiol. 46, 565-601.

44 Neidle, E.L., Hartnett, C., Ornston, L.N., Bairoch, A., 
Rekik, M. and Harayama, S. (1991) Nucleotide sequences of the Acinetobacter calcoaceticus benABC genes for benzoate 1,2-dioxygenase reveal evolutionary relationships among multicomponent oxygenases. J. Bacteriol. 173 , $5385-5395$.

45 Kurkela, S., Lehväslaiho, H., Palva, E.T. and Teeri, T.H. (1988) Cloning, nucleotide sequence and characterization of genes encoding naphthalene dioxygenase of Pseudomonas putida strain NCIB9816. Gene 73, 355-362.

46 Weijer, W.J., Hofsteenge, J., Vereijken, J.M., Jekel, P.A. and Beintema, J.J. (1982) Primary structure of $p$-hydroxy benzoate hydroxylase from Pseudomonas fluorescens. Biochim. Biophys. Acta 704, 385-388.

47 You, I.-S., Ghosal, D. and Gunsalus, I.C. (1991) Nucleotide sequence analysis of the Pseudomonas putida PpG7 salicylate hydroxylase gene (nahG) and its 3 '-flanking region. Biochemistry 30, 1635-1641.

48 Kivisaar, M., Kasak, L. and Nurk, A. (1991) Sequence of the plasmid-encoded catechol 1,2-dioxygenase-expressing gene, pheB, of phenol-degrading Pseudomonas sp. strain EST1001. Gene 98, 15-20.

49 Fukumori, F. and Hausinger, R.P. (1993) Alcaligenes eutrophus JMP134 '2,4-dichlorophenoxyacetate monooxygenase' is an $\alpha$-ketoglutarate-dependent dioxygenase. J. Bacteriol. 175, 2083-2086.

50 Nordlund, I., Powlowski, J. and Shingler, V. (1990) Complete nucleotide sequence and polypeptide analysis of multicomponent phenol hydroxylase from Pseudomonas sp. strain CF600. J. Bacteriol. 172, 6826-6833.

51 Yen, K.-M., Karl, M.R., Blatt, L.M., Simon, M.J., Winter, R.B., Fausset, P.R., Lu, H.S., Harcourt, A.A. and Chen, K.K. (1991) Cloning and characterization of a Pseudomonas mendocina KR1 gene cluster encoding toluene4-monooxygenase. J. Bacteriol. 173, 5315-5327.

52 Harayama, S., Rekik, M. and Timmis, K.N. (1986) Genetic analysis of a relaxed substrate specificity aromatic ring dioxygenase, toluate 1,2-dioxygenase, encoded by TOL plasmid pWW0 of Pseudomonas putida. Mol. Gen, Genet $202,226-234$.

53 Locher, H.H., Leisinger, T. and Cook, A.M. (1991) 4Toluene sulfonate methyl-monooxygenase from Comamonas testosteroni T-2: purification and some properties of the oxygenase component. J. Bacteriol. 173, 3741-3748.

54 Taira, K., Hayase, N., Arimura, N., Yamashita, S., Miyazaki, T. and Furukawa, K. (1988) Cloning and nucleotide sequence of the 2,3-dihydroxybiphenyl dioxygenase gene from the PCB-degrading strain of Pseudomonas paucimobilis Q1. Biochemistry 27, 3990-3996.

55 Shingler, V., Powlowski, J. and Marklund, U. (1992) Nucleotide sequence and functional analysis of the complete phenol/3,4-dimethylphenol catabolic pathway of Pseudomonas sp. strain CF600. J. Bacteriol. 174, 711-724.

56 Kohler, H.-P.E., Srhmid, A. and van der Maarel, M. (1993) Metabolism of 2,2'-dihydroxybiphenyl by Pseudomonas sp. strain HBP1: production and consumption of 2,2',3-trihydroxybiphenyl. J. Bacteriol. 175, 1621-1628.

57 Neidle, E., Hartnett, C., Ornston, L.N., Bairoch, A., Rekik,
M. and Harayama, S. (1992) Cis-diol dehydrogenases encoded by the TOL pWW0 plasmid $x y / L$ gene and the Acinetobacter calcoaceticus chromosomal benD gene are members of the short-chain alcohol dehydrogenase superfamily. Eur. J. Biochem. 204, 113-120.

58 Scholten, J.D., Chang, K.-H., Babbitt, P.C., Charest. H., Sylvestre, M. and Dunaway-Mariano, D. (1991) Novel enzymic hydrolytic dehalogenation of a chlorinated aromatic. Science 253, 182-185.

59 Imai, R., Nagata, Y., Fukuda, M., Takagi, M. and Yang, K. (1991) Molecular cloning of a Pseudomonas paucimobilis gene encoding a 17 -kilodalton polypeptide that eliminates $\mathrm{HCl}$ molecules from $\gamma$-hexachlorocyclohexane. $J$ Bacteriol. 173, 6811-6819.

60 Schmidt, E. and Knackmuss, H.-J. (1980) Chemical structure and biodegradability of halogenated aromatic compounds. Conversion of chlorinated muconic acids into maleoylacetic acid. Biochem. J. 192, 339-347.

61 Pieper, D.H., Kuhm, A.E., Stadler-Fritzsche, K.. Fischer, P. and Knackmuss, H.-J. (1991) Metabolization of 3,5-dichlorocatechol by Alcaligenes eutrophus JMP 134. Arch. Microbiol. 156, 218-222.

62 Schlömann, M., Pieper, D.H. and Knackmuss, H.-J. (1990) Enzymes of haloaromatics degradation: variations of $\mathrm{Al}$ caligenes on a theme by Pseudomonas. In: Pseudomonas: Biotransformations, Pathogenesis, and Evolving Biotechnology (Silver, S., Chakrabarty, A.M., Iglewski, B. and Kaplan, S., Eds.), pp. 185-197. American Society for Microbiology, Washington, D.C.

63 Broderick, J.B. and O'Halloran, T.V. (1991) Overproduction, purification, and characterization of chlorocatechol dioxygenase, a non-heme iron dioxygenase with broad substrate tolerance. Biochemistry 30,7349-7358.

64 Kuhm, A.E., Schlömann, M., Knackmuss, H.-J. and Pieper, D.H. (1990) Purification and characterization of dichloromuconate cycloisomerase from Alcaligenes eutrophus JMP134. Biochem. J. 266, 877-883.

65 Neidle, E.L., Hartnett, C. and Ornston, L.N. (1989) Characterization of Acinetobacter calcoaceticus cat $M$, a repressor gene homologous in sequence to transcriptional activator genes. J. Bacteriol. 171, 5410-5421.

66 Rothmel, R.K., Aldrich, T.L., Houghton, J.E., Coco, W.M., Ornston, L.N. and Chakrabarty, A.M. (1990) Nucleotide sequencing and characterization of Pseudomonas putida cat $R$ : a positive regulator of the catBC operon is a member of the LysR family. J. Bacteriol. 172, 922-931.

67 Rothmel, R.K., Shinabarger, D.L., Parsek, M.R., Aldrich, T.L. and Chakrabarty, A.M. (1991) Functional analysis of the Pseudomonas putida regulatory protein CatR: transcriptional studies and determination of the CatR DNAbinding site by hydroxyl-radical footprinting. J. Bacteriol. $173,4717-4724$.

68 Coco, W.M., Rothmel, R.K., Henikoff, S. and Chakrabarty, A.M. (1993) Nucleotide sequence and initial functional characterization of the $c l c R$ gene encoding a LysR family activator of the clcABD chlorocatechol operon in Pseudomonas putida. J. Bacteriol. 175, 417-427. 
69 Streber, W.R., Timmis, K.N. and Zenk, M.H. (1987) Analysis, cloning, and high-level expression of 2,4-dichlorophenoxyacetate monooxygenase gene $t f d A$ of Alcaligenes eutrophus. J. Bacteriol. 169, 2950-2955.

70 Henikoff, S., Wallace, J.C. and Brown, J.P. (1990) Finding protein similarities with nucleotide sequence databases. Methods Enzymol. 183, 111-133.

71 Thomas, A.W., Lewington, J., Hope, S., Topping, A.W., Weightman, A.J. and Slater, J.H. (1992) Environmentally directed mutations in the dehalogenase system of Pseudomonas putida strain PP3. Arch. Microbiol. 158, 176-182.

72 Cairns, J., Overbaugh, J. and Miller, S. (1988) The origin of mutants. Nature (London) 335, 142-145.

73 Cairns, J. and Foster, P.L. (1991) Adaptive reversion of a frameshift mutation in Escherichia coli. Genetics 128, $695-703$

74 Boe, L. (1990) Mechanism for induction of adaptive mutations in Escherichia coli. Mol. Microbiol. 4, 597-601.

75 Hall, B.G. (1991) Spectrum of mutations that occur under selective and non-selective conditions in Escherichia coli. Genetica 84, 73-76.

76 Hall, B.G. (1992) Selection-induced mutations occur in yeast. Proc. Natl. Acad. Sci. USA 89, 4300-4303.

77 Mittler, J.E. and Lenski, R.E. (1990) New data on excisions of $\mathrm{Mu}$ from $E$. coli MCS2 cast doubt on directed mutation hypothesis. Nature (London) 344, 173-175.

78 Mittler, J.E. and Lenski, R.E. (1992) Experimental evidence for an alternative to directed mutation in the $b g l$ operon. Nature (London) 356, 446-448.

79 Echols, H. and Goodman, M.F. (1991) Fidelity mechanisms in DNA replication. Annu. Rev. Biochem. 60, $477-$ 511.

80 Blom, A., Harder, W. and Matin, A. (1992) Unique and overlapping pollutant stress proteins of Escherichia coli. Appl. Environ. Microbiol. 58, 331-334.

81 Rusina, O.Y., Mirskaya, E.E., Andreeva, I.V. and Skavronskaya, A.G. (1992) Precise excision of transposons and point mutations induced by chemicals. Mut. Res. 283, $161-168$

82 Taira, K., Hirose, J., Hayashida, S. and Furukawa, K. (1992) Analysis of $b p h$ operon from the polychlorinated biphenyl-degrading strain of Pseudomonas pseudoalcaligenes KF707. J. Biol. Chem. 267, 4844-4853.

83 Wittich, R.-M., Wilkes, H., Sinnwell, V., Francke, W. and Fortnagel, P. (1992) Metabolism of dibenzo-p-dioxin by Sphingomonas sp. strain RW1. Appl. Environ. Microbiol. $58,1005-1010$.
84 Kuhm, A.E., Stolz, A., Ngai, K.-L. and Knackmuss, H.-J. (1991) Purification and characterization of a 1,2-dihydroxynaphthalene dioxygenase from a bacterium that degrades naphthalenesulfonic acids. J. Bacteriol. 173, $3795-$ 3802.

85 Kurkela, S., Lehväslaiho, H., Palva, E.T. and Teeri, T.H. (1988) Cloning, nucleotide sequence and characterization of genes encoding naphthalene dioxygenase of Pseudomonas putida strain NCIB9816. Gene 73, 355-362.

86 Yen, K.-M. and Serdar, C.M. (1988) Genetics of naphthalene catabolism in Pseudomonads. CRC Crit. Rev. Microbiol. 15, 247-268.

87 Imai, R., Nagata, Y., Fukuda, M., Yano, K. and Takagi, M. (1992) Isolation and characterization of a dehydrochlorinase gene for the degradation of $\gamma$-hexychlorocyclohexane in Pseudomonas paucimobilis. In: Pseudomonas: Molecular Biology And Biotechnology (Galli, E., Silver, S. and Withols, B., Eds.), pp. 292-300. American Society for Microbiology, Washington, D.C.

88 Xun, L. and Orser, C.S. (1991) Purification and properties of pentachlorophenol hydroxylase, a flavoprotein from Flavobacterium sp. strain ATCC 39723. J. Bacteriol. 173 , 4447-4453.

89 Xun, L., Topp, E. and Orser, C.S. (1992) Confirmation of oxidative dehalogenation of pentachlorophenol by a Flavobacterium pentachlorophenol hydroxylase. J. Bacteriol. $174,5745-5747$.

90 Furukawa, K., Arimura, N. and Miyazaki, T. (1987) Nucleotide sequence of the 2,3-dihydroxybiphenyl dioxygenase gene of Pseudomonas pseudoalcaligenes. J. Bacteriol. 169, 427-429.

91 Suzuki, M., Hayakawa, T., Shaw, J.P., Rekik, M. and Harayama, S. (1991) Primary structures of xylene monooxygenase: similarities to and differences from the alkane hydroxylation system. J. Bacteriol. 173, 1690-1695.

92 Suen, W.-C. and Spain, J.C. (1993) Cloning and characterization of Pseudomonas sp. strain DNT genes for 2,4-dinitrotoluene degradation. J. Bacteriol. 175, 1831-1837.

93 Thurnheer, T., Zürrer, D., Höglinger, O., Leisinger, T. and Cook, A.M. (1990) Initial steps in the degradation of benzene sulfonic acid, 4-toluene sulfonic acids, and orthanilic acid in Alcaligenes sp. strain O-1. Biodegradation 1, 55-64.

94 Doten, R.C., Ngai, K.-L., Mitchell, D.J. and Ornston, L.N. (1987) Cloning and genetic organization of the pca gene cluster from Acinetobacter calcoaceticus. J. Bacteriol. 169, 3168-3174. 